\title{
SCHILLER: \\ LA SENSIBILIDAD Y LOS PASOS DE LA LIBERTAD
}

Ana Isabel Illanes*

RESUMEN: A partir de su contextualización -el fracaso de la Revolución francesa-se examina la obra de Schiller, quien buscó estructurar un pensamiento que redimiera la idea de cultura, sin caer en la idealización del pasado ni en un retorno a la naturaleza; postula la libertad como juego, entre el impulso sensible y el racional: libertad en apariencia.

\section{yose}

ABSTRACT: From its contextualization -the failure of the French Revolution- we analyze Schiller's work. He proposed a theory to redeem the idea of culture without resorting to the idealization of the past or returning to nature. He presents freedom as a game, in between sensible impulse and rationality: freedom by all appearances.

PALABRAS CLAVE: Schiller, sensibilidad, libertad, razón, Estado, naturaleza. KEYWORDS: Schiller, sensibility, freedom, reason, State, nature.

RECEPCIÓN: 2 de septiembre de 2008.

APROBACIÓN: 4 de febrero de 2009.

* Departamento de Filosofía, Universidad Iberoamericana. 
CITAM Derechos Reservados.

La reproducción total o parcial de este artículo se podrá hacer si el ITAM otorga la autorización previamente por escrito. 


\title{
SCHILLER: \\ LA SENSIBILIDAD \\ Y LOS PASOS DE \\ LA LIBERTAD
}

\section{La reforma del Estado: entre la estética y la ética}

\author{
El pensamiento de Schiller, tanto
} político como estético, se debe abordar en muchos de sus aspectos tomando en cuenta el fracaso de la Revolución francesa. Tras la barbarie suscitada por dicha revolución, en donde se manifiesta una liga entre la razón y el terror, en sus Cartas sobre la educación estética del hombre pone en tela de juicio la efectividad de la razón práctica, de la razón política: se cuestiona la posibilidad de la construcción moral del mundo a través de medios únicamente políticos. Su pensamiento intenta una reforma del Estado que incluye proporcionar una nueva forma a la razón que evite el peligro que trae consigo una época de terror. Sin postular un retorno a la naturaleza y contrario a la idealización del pasado de la humanidad, Schiller, a diferencia de Rousseau, quien reniega de la cultura, considera que el paraíso de la vida natural quedó en el pasado y no postula un hombre que, privado de las relaciones sociales, se esconda como un troglodita. Partiendo de los presupuestos morales de la filosofía kantiana (a quien comienza a estudiar en 1791), intenta la redención de la cultura. Pero, a diferencia del planteamiento de Kant ${ }^{1}$-para

${ }^{1}$ Así, en asuntos de interés público, Kant apela a una "uniformidad artificial” en virtud de la cual los miembros del Estado deben comportarse pasivamente; éstos no pueden razonar, sino sólo obedecer para que el gobierno los guíe hacia los fines públicos. Véase Kant, Respuesta a la pregunta: ¿Qué es la Ilustración?, 1999, Madrid, Editorial Tecnos, trad. José Romagosa, pp. 17-29. 
quien sólo podemos esperar el progreso de un aumento en la legalidad con instituciones cimentadas sobre el derecho que hagan respetar la ley de un modo coactivo-, Schiller intenta una reforma individual del carácter: una reforma de cada hombre que no excluye su libertad.

En el diagnóstico que hace sobre su tiempo denuncia a los Estados que se encuentran cegados por el egoísmo y a los ciudadanos que permanecen preocupados únicamente con su bienestar físico y material: que sólo procuran su provecho, su utilidad individual. Hace una crítica de la generación presente, ya que desde su óptica estos hombres no supieron aprovechar el favor del momento, no estuvieron a la altura de la libertad externa que habían conquistado, al encontrarse dominados por la naturaleza sin poderse dominar a sí mismos. Pone en cuestión los principios de la Ilustración, ya que éstos se han quedado en mera cultura teórica, en meras abstracciones, y aunque reconoce que éstos son racionalmente verdaderos y moralmente correctos, están lejos de ser efectivos y más bien han provocado situaciones extremas de salvajismo y barbarie. Denuncia a la razón ilustrada -y al hacerlo se cuestiona la eficiencia de la filosofía moral kantiana de la que él mismo parte-, ya que ésta ha dado pocas muestras victoriosas de fuerza, al encontrarse desvinculada del corazón, quien ya no la escucha, y del impulso que ya no actúa en su favor. Así, menciona:

La necesidad más imperiosa de nuestra época me parece que es el ennoblecimiento de los sentimientos y la purificación moral de la voluntad, ya que se ha hecho mucho por la ilustración del entendimiento. De esta forma no nos falta tanto conocimiento para la determinación de la voluntad y del derecho, como efectividad de este conocimiento para la determinación de la voluntad, no tanta luz como calor, y no tanta cultura filosófica como estética. ${ }^{2}$

Schiller realiza una crítica al predominio de la facultad analítica en el pensamiento ilustrado; para él, dicho predominio lleva a un empobrecimiento de la fantasía humana, ya que le quita su fuerza y su energía,

${ }^{2}$ Schiller, Escritos de filosofía de la historia, 1991, Murcia, Universidad de Murcia, Trad. Lucía Camarena, pp. 104-5. 
y produce pensadores abstractos de corazón frío que fraccionan las impresiones; pensadores con una imaginación carente de sensibilidad que, recluidos en el ámbito uniforme de su actividad, se tornan incapaces de alcanzar otras formas de representación. Desde su óptica, el hombre de hoy, heredero del pensamiento analítico, evoluciona como fragmento, no desarrolla la armonía que lleva dentro, y en lugar de imprimir a su naturaleza el carácter propio de la humanidad, se convierte en un reflejo de su oficio, de su ciencia. Denuncia al hombre moderno que, inmerso en la división del trabajo, se encuentra excesivamente especializado y ajeno a los problemas de la vida cotidiana; a ese hombre para quien los límites de su oficio (en su mayoría burocrático) donde consume sus escasas fuerzas, se tornan también los límites de su actividad.

Schiller, como nos dice Habermas, ${ }^{3}$ concibe la modernidad en discordia consigo misma, como una serie de instancias separadas y contrapuestas que luchan en el seno del hombre moderno, ese ser escindido, producto de una cultura teórica predominantemente analítica que, como herencia de la filosófica dualista kantiana, manifiesta un aislamiento de las facultades; una separación entre la razón y la sensibilidad; entre espíritu especulativo y práctico; entre ciencias y arte; entre sociedad e individuo, cosa que propicia el desarrollo de determinadas tendencias en detrimento de otras que llegan a atrofiarse.

Y es este mal de su tiempo el que nuestro pensador pretende remediar. Parte de las mismas ideas kantianas, las que considera sentencias antiquísimas de la razón común, pero liberadas del inconveniente de su forma técnica, de su forma analítica y de su efecto disolvente que divide, separa e imposibilita el reconocimiento del sentimiento natural. Para el filósofo-poeta, hay que apelar a un corazón capaz de sentir todo su poder: que tome en cuenta tanto sentimientos como principios, tanto a la sensibilidad como a la razón, y que logre una armonía entre ambos que nos impida caer en la barbarie o en el salvajismo. Intenta superar el dualismo que sólo consigue la unidad desde la subordinación que nos lleva a la uniformidad, mas no la armonía. A través de toda su

${ }^{3}$ Véase Jürgen Habermas, El discurso filosófico de la modernidad, 1989, Buenos Aires, Editorial Taurus, trad. Manuel Jiménez Redondo, pp. 62-7. 
ANA ISABEL ILLANES

obra vemos un intento armonizador que respeta las dos instancias; para él los sentimientos no deben dominar sobre los principios, ni despreciar la cultura, pero tampoco los principios deben destruir a los sentimientos. No se debe difamar a la naturaleza ni burlarse de ella, más bien hay que conducirse amistosamente con ella.

Pero la crítica schilleriana a la fragmentación en la que se encuentra inmerso el hombre moderno presenta una ambigüedad, muestra otro rostro. Si la vemos desde el punto de vista de la historia de la humanidad, la fragmentación, el antagonismo de las fuerzas se muestra como algo necesario para el desarrollo de la cultura y de la técnica: para el progreso. ${ }^{4}$ Schiller nos dice que la acumulación tan enorme de saber de nuestra modernidad obligó al entendimiento a separarse de la sensación y de la intuición, para buscar un conocimiento claro de las cosas.

Una práctica unilateral de las facultades humanas lleva al individuo inevitablemente al error, pero conduce a la especie hacia la verdad. Sólo reuniendo toda la energía de nuestro espíritu en un punto, y concentrando todo nuestro ser en una sola de nuestras facultades, damos alas a esa facultad, y la llevamos artificialmente mucho más allá de los límites que la naturaleza parece haberle impuesto. ${ }^{5}$

Pero, aunque Schiller menciona en concordancia con las teorías teleológicas que el antagonismo de fuerzas fue el gran instrumento

${ }^{4} \mathrm{~A}$ lo largo de los escritos de Schiller se puede percibir un entusiasmo y a la vez un cuestionamiento a la idea del progreso de la humanidad. Por un lado, en la lección inaugural de la Universidad de Jena (1789) menciona que "se ha conseguido mucho" y nos invita a considerar a la historia como el enorme campo de trabajo de la humanidad, pues quien lo hace se libera de los juicios limitados del egoísmo y ve su destino enlazado con la gran historia que "imperceptiblemente" conduce al individuo, aún al egoísta, hacia el progreso. Pero, por otro lado, en la misma época, en El visionario (1789), encontramos un clima de oscuridad, de escepticismo y desesperación; nos muestra una razón cavilante para la que sólo hay presente y el todo histórico se da como construcción intelectual o como una fantasía. Cf., Schiller, El visionario, 1986, Barcelona, Editorial Icaria, trad. Antonio Bueno. Sostiene que la cadena de los efectos es impredecible, y utiliza la imagen de un mensajero indiferente al contenido del mensaje que lleva. Véase Rüdiger Safranski, Schiller o la invención del idealismo alemán, 2006, Barcelona, Tusquets Editores, trad. de Raúl Gabás, pp. 310-4.

${ }^{5}$ Schiller, Cartas sobre la educación estética del hombre, 1999, Barcelona, Editorial Anthropos, trad. Jaime Feijóo y Jorge Seca, p. 157. 
de la cultura que nos llevo a un progreso, para el filósofo resulta falso que el desarrollo aislado de las facultades, así como su conflicto, haga necesario el sacrificio de la totalidad. Más bien, desde su óptica, debemos acabar con dicha escisión, con la tiranía de la razón sobre la sensibilidad, que según Marcuse, ${ }^{6}$ llega a ser la enfermedad de la civilización. Debemos restablecer la armonía en nuestra naturaleza humana, restablecer la totalidad que la cultura ha destruido mediante otra cultura más elevada que permita la realización de los presupuestos supremos de la razón, para dar lugar a hombres felices y perfectos. De tal manera que suprimir esa fragmentación, esa escisión en el interior del hombre se torna, para el pensador, una tarea prioritaria, a tal punto que llega a afirmar que sería prematuro todo intento de reforma del Estado si no se suprime antes dicha escisión. Antes de favorecer la multiplicidad del género humano, se debe calmar el antagonismo que reina en cada hombre, equilibrar las luchas de sus fuerzas elementales, la pugna de sus impulsos ciegos, pues, para que la multiplicidad humana pueda someterse a la unidad del ideal la independencia de su carácter, debe estar asegurado, y el sometimiento a formas ajenas debe haber dejado espacio a, lo que para él es más importante: una aceptable libertad.

Schiller afirma que su interés principal no es el arte, sino alcanzar la nobleza moral en el hombre; nos dice: "que la más perfecta de las obras de arte, [es] la construcción de una verdadera libertad política"? Y en la carta del 13 de julio al príncipe de Augustenburgo afirma que si ya se hubiera dado de hecho una legislación política transferida a la razón, donde el hombre fuera respetado y tratado como un fin en sí mismo, y la verdadera libertad ya estuviera instituida como principio básica de la construcción del Estado,

entonces me gustaría despedirme para siempre de las musas y dedicar toda mi actividad a la más señorial de todas las obras de Arte, a la monarquía de la razón. Pero es de este hecho precisamente del que dudo. Estoy tan lejos de creer en el comienzo de una regeneración en lo

${ }^{6}$ Véase Herbert Marcuse, Eros y civilización, 2001, Barcelona, Editorial Ariel, trad. Juan García Ponce, p. 179.

${ }^{7}$ Schiller, Cartas sobre la educación estética del hombre, op. cit., p. 157. 
político, que los acontecimientos de la época me privan por siglos de toda esperanza de alcanzarlo. ${ }^{8}$

Su punto de partida, como paso previo a la reforma de lo político y a los problemas que enfrenta la modernidad, será el ennoblecimiento del carácter humano, que conlleva una relación nueva con la sensibilidad. Así, la creación de un nuevo hombre mediante la educación estética se da a partir de la educación de la sensibilidad y no a partir de su aniquilación. Bajo la presión de los acontecimientos históricos que demandan su completa atención, nuestro pensador intenta una nueva manera de abordar el problema de la belleza, que contempla una investigación de los efectos de la belleza sobre las funciones sociales y políticas. Como respuesta a la alternativa de la nación política de la Francia revolucionaria, Schiller postula la creación de una nación cultural donde la libertad del individuo juega el papel preponderante. La solución de la problemática política, si bien se debe dar en la experiencia, requiere para Schiller de la vía estética, que concibe como inseparable de la libertad, ya que para él "es a través de la belleza como se llega a la libertad". ${ }^{9}$ Desde una postura secularizada nos receta el arte: "porque el arte es hijo de la libertad y sólo ha de regirse por la necesidad del espíritu, no por meras exigencias materiales". ${ }^{10} \mathrm{Y}$ con esto, nuestro pensador desplaza el centro de la esfera política hacia a la educación estética, abriendo para el pensamiento una serie de posibilidades, no exentas de problemas.

Así, al realizar la tarea que se propone a lo largo de su pensamiento -la de reconciliar y armonizar el abismo entre necesidad y libertad, que se traduce en las oposiciones entre sensibilidad y razón, materia y forma, ser y deber-ser, felicidad y moralidad, individuo y sociedad, así como entre individuo y Estado-, la belleza toma un lugar único y logra salirse de alguna manera de la férula de la razón, de la ley moral, llegando a adquirir autonomía, que abre al pensamiento nuevas alter-

${ }^{8}$ Schiller, Escritos de filosofía de la historia, op. cit., p. 100.

${ }^{9}$ Schiller, Cartas sobre la educación estética del hombre, p. 121.

${ }^{10}$ Ibid., p. 117. 
nativas y problemáticas, entre las que destacan una nueva manera de abordar tanto la libertad como la sensibilidad, que termina por rehabilitar a la misma sensibilidad. Todo esto, al replantear la relación entre la sensibilidad y la libertad, entre sensibilidad y ley moral.

\section{La libertad como juego: entre el impulso sensible y el impulso racional}

Si abordamos el pensamiento de Schiller sobre el ser humano, vemos que éste parte del dualismo presente en la filosofía kantiana. El filósofo-poeta concibe en el hombre dos impulsos, dos leyes indestructibles inscritas en su naturaleza. "Una conciencia incorruptible le ha inculcado la ley de la razón, y la ley natural le viene dada por un sentimiento indestructible". ${ }^{11}$ Por una parte, el impulso racional, también llamado impulso formal que despierta con la experiencia de la ley (dicta leyes) y que, como consecuencia de nuestra existencia absoluta, de nuestra naturaleza racional, nos proporciona libertad. Por otra parte, el impulso sensible que, como resultado de nuestra existencia material, nos sitúa dentro de los límites del tiempo. Este impulso despierta con la experiencia de la vida y sólo da lugar a casos individuales y concretos. Conforme a estos dos impulsos, el hombre es reclamado por dos legislaciones contrapuestas, dos instancias constitutivas: una legislación que se encuentra guiada por la razón, que sólo se da por satisfecha si su ley se impone sin condiciones y exige unidad; mientras que otra, guiada por la naturaleza, exige variedad.

La cuestión será, ¿cómo superar la oposición entre estas dos legislaciones, entre el carácter moral y el carácter natural? ¿Cómo mantener la armonía entre ambos? En un primer momento Schiller reconoce que "la distancia que existe entre materia y forma, entre pasividad y actividad, entre sensación y pensamiento, es infinita, y no hay nada que pueda salvarla". ${ }^{12}$ Pero también añade que la belleza entrelaza los dos

${ }^{11}$ Ibid., p. 131.

${ }^{12}$ Ibid., p. 261. 
estadios contrapuestos del sentir y del pensar sin que exista ningún término medio ente ambos. Sostiene que la contraposición de estos dos impulsos y legislaciones no es meramente lógica ni tampoco conceptual, sino que se encuentre inscrita en nuestra misma realidad sensible-racional, sin que esto signifique que estos impulsos y legislaciones contrapuestas se opongan por naturaleza; para él, no se contradicen en un mismo objeto, $\mathrm{y}$ donde no hay contacto no puede haber choque, y si aparecen con ese carácter opuesto, es que han confundido su ámbito de acción. ${ }^{13}$

El fundamento de la unión de estos dos impulsos Schiller lo encuentra en el hombre. De tal manera que no podemos afirmar un antagonismo originario en el impulso racional y el sensible sin deshacer la unidad del hombre. Se muestra contrario a cualquier tipo de subordinación, ya sea del impulso sensible al racional, como del racional al sensible. Si el carácter moral se afirmara mediante el sacrificio del carácter natural, para el filósofo resultaría una uniformidad sin armonía, el hombre quedaría dividido para siempre. Si la persona sustituye al mundo, ésta dejaría de ser fuerza autónoma y sujeto para tomar el lugar del objeto. Y si se diera lo contrario, si el impulso sensible actuara de manera exclusiva sin aceptar una forma, estaríamos sumidos en la variedad sin alcanzar la unidad: el hombre se volvería una magnitud, un momento lleno de contenido y desaparecería dominado por las sensaciones y el tiempo. No sería él mismo, su personalidad terminaría sometida al mundo que dejaría de ser objeto y se transformaría en poder. Cosa muy diferente si se da la armonía que Schiller intenta, pues en este caso el hombre en lugar de perderse en el mundo, lo aprehendería junto a la totalidad infinita de sus fenómenos dentro de sí, y lo sometería a la unidad de la razón. Schiller propone:

Para no ser mero mundo, el hombre ha de darle forma a la materia; para no ser mera forma, tiene que dar realidad a la disposición que

${ }^{13}$ Para Paul de Man se da una reversibilidad entre estos dos impulsos, nunca se encuentran el uno con el otro, cosa que hace que no entren en una relación dialéctica. La posibilidad de esta síntesis se hace en nombre de un concepto pragmático empírico, el de la humanidad, que sirve como clausura y que no está abierto a ningún discurso crítico. Humanidad que es equiparada a la relación de equilibrio entre necesidad y libertad. Véase Paul de Man, La ideología estética, 1998, Madrid, Editorial Cátedra, trad. Manuel Asensi y Mabel Richard, pp. 213-4. 
lleva en sí. Hace real la forma al crear el tiempo y al oponer la variación a lo permanente, la multiplicidad del mundo a la unidad eterna de su yo; da forma a la materia volviendo a suprimir el tiempo, afirmando la persistencia en la variación, y sometiendo la variedad del mundo a la unidad del yo. ${ }^{14}$

Para Schiller, es necesario que los efectos de esos dos impulsos, el material y el formal, coincidan plenamente en el reino de los fenómenos; que, a pesar de su extrema diferencia formal, coincidan para hacer posible una legislación universal. De ahí que la tarea de la cultura consista en vigilar estos impulsos y asegurar sus límites haciendo justicia a ambos. El quehacer será doble: proteger a la sensibilidad de los ataques de la razón y asegurar la personalidad frente al poder de la sensibilidad, lo cual se consigue por medio de la educación estética, pues sólo la belleza hace posible educar simultáneamente la facultad sensible y la facultad racional de la naturaleza humana, ya que las contiene a ambas.

Pero como en el placer que nos proporciona la belleza o la unidad estética, se da una unión y una permutación reales de la materia con la forma, y de la pasividad con la actividad, queda probada así la compatibilidad de ambas naturalezas, la viabilidad de lo infinito en el seno de la finitud, y con ello la posibilidad de la humanidad más sublime. ${ }^{15}$

Schiller apela a una facultad nueva y autónoma que permitirá que la belleza pueda ser un medio que conduzca a los hombres de la materia a la forma, de lo limitado a lo absoluto. Es preciso llegar a la unidad de dichos impulsos, armonizarlos por la belleza, para que el hombre alcance la máxima autonomía y libertad con la máxima plenitud del ser, ya que si dejamos que los dos impulsos actúen en el hombre, éstos

${ }^{14}$ Schiller, Cartas sobre la educación estética del hombre, p. 199. Schiller establece que lo permanente exige variación, y la realidad absoluta requiere límites para manifestarse: la variación exige algo permanente, y la realidad limitada requiere una realidad infinita.

${ }^{15}$ Ibid., p. 341. 


\section{pierden su carácter coactivo, pues según Schiller: "la contraposición de dos necesidades da origen a la libertad". ${ }^{16}$}

Dado que el ánimo, al contemplar la belleza, se encuentra en un afortunado punto medio entre la ley y la necesidad, se sustrae de este modo a la coacción tanto de la una como de la otra, porque se reparte entre ambas. ${ }^{17}$

Bajo la influencia de Fichte, Schiller postula una acción recíproca entre el impulso sensible y el formal a partir del impulso de juego. Postula al impulso del juego como principio de acción de la belleza, que "se encaminaría a suprimir el tiempo en el tiempo, a conciliar el devenir con el ser absoluto, la variación con la identidad". ${ }^{18}$ La función de dicho impulso será englobar a estos impulsos respetándolos en un movimiento que, suprimiendo y conservando, se acerca a la dialéctica hegeliana, ${ }^{19}$ donde sólo en lo reconciliado las oposiciones quedan vencidas, mientras que el impulso sensible coacciona mediante las leyes naturales; se refiere a la realidad de las cosas y aspira a conservar la vida, ya que

${ }^{16} \mathrm{Ibid}$., p. 279. Y aquí se refiere a una libertad que no es la que atañe necesariamente al hombre en cuanto ser racional, sino a aquella otra libertad que se basa en su doble naturaleza y que es una posibilidad natural de la primera. El hecho de que no se pueda actuar sobre la libertad, se desprende de su concepto, del que "se sigue necesariamente que la libertad misma es un efecto de la naturaleza [...] y no una obra del hombre, y que, por consiguiente, también puede ser activada y frenada por medios naturales", ibid., p. 281.

${ }^{17}$ Ibid., p. 235.

${ }^{18} \mathrm{Ibid}$., p. 225. Schiller retoma el concepto de juego que aparece en Kant, a partir del juego libre de las facultades de conocimiento. El juego representa para Kant una relación incondicionada, estructuralmente libre, entre imaginación y entendimiento, siendo la libertad y la subjetividad las dos características fundamentales de su concepto de juego. Véase Kant, Crítica del juicio, 1973, México, Editorial Porrúa, trad. Manuel García Morente, a partir del § 9 , p. 218.

${ }^{19}$ Contrario al acercamiento dialéctico que proponemos, Paul de Man señala que Schiller empieza con una polaridad absoluta entre impulsos, no puede escribir dos frases que no estén simétricamente determinadas por un quiasmo, por esa estructura reversible y simétrica. Y el juego, que tiene esa función placentera, tranquilizadora y armonizadora, es el espacio que se necesita para evitar que se produzca el encuentro dialéctico. Hay dialéctica cuando hay labor de lo negativo, encuentro con la negación, cosa que no está en Schiller, para quien la armonía no debe ser perturbada, para quien los opuestos no deben coincidir y no hay mediación. De Man reconoce que hay momentos dialécticos en su obra teatral, pero no en sus ensayos filosóficos. Paul de Man, op. cit., pp.185-224. 
su objeto es la vida en su más amplio sentido; el impulso formal coacciona mediante leyes racionales: hace referencia a la necesidad de las cosa y aspira a preservar la dignidad, siendo su objeto la Forma (Gestalt). El objeto del impulso de juego es la Forma viva; éste designa todas las cualidades estéticas de los fenómenos, lo que denominamos belleza en su más amplia acepción. ${ }^{20}$

Desde este orden de ideas, la belleza a la que se debe tender sólo se alcanza mediante el juego libre y uniforme de los miembros, donde opera tanto la distensión que contiene en sus límites, como la tensión que mantiene las fuerzas de ambos, cosa que no trae consigo la supresión de uno de estos impulsos, antes bien, "la actividad de uno fomenta y limita al mismo tiempo la actividad del otro, y [...] cada uno de ellos por sí mismo alcanza su máxima manifestación justamente cundo el otro está activo". ${ }^{21}$ La distensión del impulso sensible no debe ser efecto de una incapacidad física, ni de un embotamiento de los sentidos, sino una acción de la libertad de la persona que, mediante su intensidad moral, modere la intensidad sensible. La fuente de la distensión del impulso formal ha de ser la plenitud de las sensaciones, que defiende su territorio contra la precipitada actividad del espíritu.

Aunque el juego se defina como libertad frente a la coacción de los impulsos, como la puesta en práctica de la libertad, esto no significa en manera alguna que se encuentre libre de leyes, que sea arbitrario; más bien, para Schiller, el juego designa todo lo que no es ni subjetiva ni objetivamente arbitrario, y que sin embargo no coacciona ni interior ni exteriormente. La libertad no consiste en la carencia de leyes, sino en la armonía de las leyes y la belleza: no es arbitrariedad, sino suprema necesidad interna.

Schiller concibe al juego como símbolo del cumplimiento de la determinación humana y llega a decir que el hombre sólo es enteramente hombre cuando juega. Para nuestro pensador, de todos los estados del hombre sólo el juego despliega su doble naturaleza, haciendo perfecto al hombre, ya que es el único que puede liberar al hombre tanto

${ }^{20}$ Para Schiller, la belleza no es solamente vida, como pensaban Burke y los empiristas escoceses; ni forma pura, como la entendían los racionalistas.

${ }^{21}$ Ibid., p. 223. 
ANA ISABEL ILLANES

física como moralmente al conjugar lo que la moral kantiana había separado: la inclinación y el deber. ${ }^{22}$ Schiller ve una salida al dualismo imperante en la disposición estética del juego, ya que esta disposición hace posible experimentar la plenitud sensible del mundo, a la vez que constituye un triunfo moral sobre el mismo. En dicha disposición, se da la contemplación libre; el hombre entra en el mundo de las ideas sin abandonar por ello el mundo sensible, cosa que, para el filósofo, lleva a la disposición estética del juego a una reconciliación, a una armonía entre necesidad y libertad. Así, el impulso del juego:

En su objeto, sustituirá la materia por la forma, y la forma por la materia; en su sujeto, transformará necesidad en libertad y libertad en necesidad, y alcanzará de este modo la más íntima conjunción de ambas naturalezas en el hombre. ${ }^{23}$

\section{Estado e individuo: libertad estética y sensibilidad}

Si atendemos a una segunda oposición existente, que Schiller percibe entre el Estado moderno y los individuos, su diagnóstico - que se acerca al planteamiento de Romanticismo y que tiene como antecedente su oposición originaria a toda clase de tiranía- nos habla de un Estado mecánico ajeno a los ciudadanos, ajeno al sentimiento, donde la clase

${ }^{22}$ Ya en Sobre la gracia y la dignidad, Schiller nos habla de la llamada "alma bella" en “donde armonizan la sensibilidad y la razón, la inclinación y el deber", Schiller, Sobre la gracia y la dignidad, 1985, Barcelona, Editorial Icaria, trad. Juan Probst y Raimundo Lida, p. 45. Y en esa misma obra menciona que, en un sentido objetivo, se oponen inclinación y deber, mientras que en un sentido subjetivo, el hombre debe enlazar el placer al deber: debe obedecer alegremente a su razón y no debe arrojar como una burda envoltura su naturaleza sensible, sino debe unirla hasta lo más íntimo con su yo superior. Habla sobre la dureza de la idea de deber kantiana, la cual espanta a todas las Gracias. Y en las Cartas sobre la educación estética pone como ejemplo a los griegos, quienes: "liberaron a los eternamente felices de las ataduras de toda finalidad, de todo deber, de toda preocupación, y convirtieron el ocio y la despreocupación en el envidiable destino de la condición divina [...]Tanto la coacción material de las leyes naturales, como la coacción espiritual de las leyes morales, se fundieron en el concepto más elevado de necesidad que poseían los griegos, el cual abarcaba ambos mundos al mismo tiempo, y sólo de la unión de ambas necesidades surgió para ellos la verdadera libertad." Schiller, Cartas sobre la educación estética del hombre, p. 243.

${ }^{23}$ Ibid., p. 229. 
dirigente pierde de vista y confunde a los ciudadanos con una obra imperfecta del entendimiento, y éstos reciben con indiferencia determinadas leyes que muy poco tienen que ver con ellos mismos. Percibe al Estado actual como un todo que se impone sin considerar a los individuos, sin considerar su libertad; un Estado que toma a los individuos como seres aislados, sólo unidos con el todo por una parte escasa y fragmentaria que no depende de formas que ellos se den a sí mismos, sino que se les prescribe una serie de leyes que paralizan la actividad de su inteligencia libre. Con todo esto, nos dice Schiller, la vida del individuo se ve aniquilada poco a poco, para que este todo absoluto - que no atiende a lo singular, que simplifica y clasifica a la multiplicidad de los ciudadanos- siga manteniendo su miserable existencia.

Schiller se cuestiona ciertos planteamientos kantianos que presuponen a un individuo obediente, sometido al poder del Estado, aceptando su supremacía. Así, la filosofía kantiana de la historia sacrifica al individuo en aras del progreso social y logra determinar la libertad interior del individuo, al mismo tiempo que subordina a los diferentes estamentos sociales. Ante todo esto, nuestro filósofo propone un Estado que mantenga la armonía, donde las partes coincidan en la idea del todo. Le interesa preservar la armonía interna del hombre mantener a salvo su singularidad, aún en el caso de que adecue sus actos a la regla de conducta universal. Tanto en las Cartas sobre la educación estética como en Sobre la gracia y la dignidad, propone a la cultura griega como modelo para una nueva totalidad inédita que parta de un nuevo ideal de humanidad. ${ }^{24}$ Contrapone la naturaleza multiforme que, desde su óptica, tenían los antiguos Estados griegos - donde cada individuo gozaba de una vida independiente y a la vez podía identificarse con el todo- con el mundo moderno donde predomina un artificio mecánico de relojería formado a partir de la concatenación de un núme-

\footnotetext{
${ }^{24}$ Schiller, influenciado por Winckelmann, Goethe y Humboldt, contrapone el carácter fragmentario de la cultura ilustrada con el sentido de totalidad y unidad de la sociedad griega. Pero, mientras que para Winckelmann, Grecia es todavía una presencia real, para Schiller es ya un anhelo que sólo se justifica como tal. Véase Johann Winckelmann, Reflexiones sobre la imitación de las obras griegas en la pintura y la escultura, 2008, México, Fondo de Cultura Económica, trad. Salvador Mas.
} 
ro infinito de partes que carecen de vida propia. Denuncia la vida mecánica y artificial que se da en el mundo moderno, para el que tanto Estado e Iglesia como leyes y costumbres se encuentran separados, y el placer permanece desvinculado del trabajo.

Para resolver estos problemas, Schiller se vale del Estado estético. Desde su óptica, el Estado estético deja en suspenso la jerarquía social; introduce armonía en la sociedad porque introduce previamente armonía en el individuo. Es el único que puede formar a la sociedad real, al referirse a lo que hay en común en todos los hombres y al cumplir la voluntad del conjunto mediante la naturaleza del individuo. Todas las otras formas de representación dividen al hombre y a la sociedad -ya sea, al basarse exclusivamente en su componente sensible o exclusivamente en su componente espiritual, o, en su defecto, al referirse únicamente a la esfera privada del sentir o del actuar de cada uno de los miembros-; sólo la dimensión estética puede lograr que la unidad social sea producida desde abajo, partiendo de la sociedad civil estéticamente transformada, en ningún caso legislada de manera arbitraria desde arriba. Sólo a la belleza la disfrutamos como individuos y como especie; sólo ella puede dar al hombre un carácter social. "Únicamente la belleza es capaz de hacer feliz a todo el mundo, y todos los seres olvidan sus limitaciones mientras experimentan su mágico poder". ${ }^{25}$

En las Cartas sobre la educación estética, Schiller reflexiona sobre la relación que debe imperar entre individuo y Estado; se cuestiona la posibilidad del ennoblecimiento humano; se pregunta: ¿cómo puede darse el ennoblecimiento del hombre en el seno de una constitución política degenerada que no atiende a la libertad? Para responder a esta cuestión, el filósofo-poeta realiza una investigación del origen de la belleza en el ánimo humano, que lo lleva a una investigación de la génesis de la libertad humana; todo esto, con el fin justificar la existencia de una libertad anterior, primera, que permita el ennoblecimiento del hombre antes de la formación del Estado. Necesita explicar el paso de la humanidad, para él peligroso, de un estado de naturaleza (que hereda de Hobbes) a un Estado moral donde la racionalidad

${ }^{25}$ Schiller, Cartas sobre la educación estética del hombre, p. 377. 
ética (herencia kantiana) y la razón contractual (herencia de Rousseau) se encuentran presentes. Así, en un primer momento, su investigación nos habla de un primer estado: un estado de necesidad que surgió sólo y exclusivamente de la determinación natural del hombre. Nos dice que la coacción de las necesidades precipitó al hombre en el estado de necesidad "antes de que pudiera elegir libremente; la necesidad lo implantó con arreglo a leyes puramente naturales, antes de que él [el hombre] pudiera implantarlo conforme a las leyes de la razón". ${ }^{26}$ En un segundo momento, aborda el paso del estado natural de necesidad al estado moral, a un estado contractual que el hombre se da a sí mismo como producto de su elección libre, ya que, desde su concepción, el hombre se hace hombre cuando, mediante su razón, se encuentra en condiciones de rehacer y "transformar la obra de la mera necesidad en obra de su libre elección y de elevar la necesidad física a necesidad moral". ${ }^{27}$

Pero este paso de estados llega a ser para Schiller sumamente problemático. Existe en esta transformación un gran riesgo que se debe, al menos en parte, a que el hombre físico y la sociedad física del estado natural son reales y no pueden detenerse en el tiempo, so pena de poner en peligro su existencia, mientras que el estado moral sólo es un supuesto. Y si la razón suprime al estado natural para dar paso al moral, arriesga al hombre físico y real en pro de un supuesto: de un ideal de sociedad que, aunque moralmente necesario, es sólo posible. El riesgo se agranda, ya que Schiller le concede a la razón la capacidad de despojar al hombre

${ }^{26}$ Ibid., p.123.

${ }^{27}$ Ibid., p. 121. Ya en su tesis doctoral (1779) Filosofía de la fisiología, que se desarrolla en las fronteras entre la medicina y la filosofía, encontramos un gran interés por el tema de la libertad, vemos un intento de encontrar y explicar la libertad y la espontaneidad en los procesos fisiológicos. Así, en Los bandidos, obra que trabaja al mismo tiempo que su tesis, intenta poner de manifiesto el mecanismo por el cual un cuerpo perturbado, como es el caso de Franz Moor, produce a su vez la perturbación del espíritu. Schiller, Los bandidos, 2006, Madrid, Editorial Cátedra, trad. J. A. Calañas Continente. Por un lado se encuentra cerca del materialismo, mientras que, por otro, adopta la tesis sobre el amor como principio cósmico, influenciado por la teoría de la felicidad y de la simpatía universal de Schaftesbury. Para responder al dualismo imperante entre materia y espíritu, Schiller utiliza la imagen de la "gran cadena de los seres vivientes", la cual percibe como una ley bella y sabia que expresa la conexión universal de la naturaleza, filosofía que perderá su predominancia cuando Schiller se acerque a Kant. Véase Safranski, op. cit., p. 75 y siguientes. 
incluso de su componente animal, que también es condición de su humanidad, a cambio de una humanidad que aún no posee y de la que puede prescindir sin menoscabo de su existencia.

Contrario a la idea de destruir al Estado y luego inventar otro nuevo (cosa que de alguna manera intento la Revolución francesa), Schiller afirma que es necesario concebir una sociedad que pueda perpetuarse "en plena marcha", para lo cual se requiere de un apoyo que haga a dicha sociedad independiente del estado natural, pero siempre asegurando la existencia física de los hombres. Este apoyo no está en el carácter natural del hombre, que para Schiller, siguiendo a Kant, es egoísta $\mathrm{y}$ violento, y que tiende antes a la destrucción de la sociedad que a su conservación. El hombre en estado natural es, para Schiller, comparable con los Titanes, ya que desconoce su dignidad humana y está lejos de respetar la de los demás. Éste es:

Un ser siempre uniforme en sus fines, y eternamente variable en sus juicios, egoísta sin ser él mismo, desatado sin llegar a ser libre, esclavo sin servir a ninguna regla. En esta edad, el mundo sólo significa destino para él. [...] Los fenómenos se le presentan aislados y separados de todos los demás, tal y como el mismo se ve en la sucesión de los seres. Todo lo que existe, existe para él según la sentencia del instante, toda variación le parece una creación completamente nueva, porque, junto a lo necesario en él, falta la necesidad fuera de él..$^{28}$

Pero si la solución no está en el carácter natural, tampoco está en el carácter moral que se encuentra en vías de formación; además, éste es "un carácter en el que el legislador no podría basarse ni confiar plenamente, porque es libre y porque nunca se manifiesta como fenómeno". ${ }^{29}$ La solución del problema, que representa una de sus mayores aportaciones, la encuentra Schiller en un tercer carácter: uno estético

${ }^{28}$ Schiller, Cartas sobre la educación estética del hombre, pp. 317-9. Pero debemos señalar que este estado de tosca naturaleza no se encuentra en ningún pueblo ni edad determinados, ya que es una pura idea con la que coinciden ciertos rasgos de la existencia. Pero aunque el hombre no se ha hallado inmerso del todo en este estado animal, tampoco ha podido evitarlo por completo.

${ }^{29}$ Ibid., p. 127. 
que haga concordar el carácter físico con las leyes, que logre que el moral dependa de las impresiones, garantizando la continuidad del estado natural a un estado basado en principios morales. Schiller postula un tercer carácter que posibilita el tránsito, desde el dominio de las fuerzas naturales, donde el hombre soporta pura y simplemente el poder de la naturaleza, al dominio de las leyes: un tercer carácter que, sin poner trabas al desarrollo del carácter moral, debe ser garantía sensible de esa invisible moralidad. Todo ello evitando la inquietud, el temor y el terror, efectos de una razón que, equivocando su objeto, impone su imperativo directamente a la materia; que no ha tomado en cuenta que "no hay otro camino para hacer racional al hombre sensible que el hacerlo previamente estético". ${ }^{30}$ Tanto el estado moral como el lógico sólo pueden desarrollarse a partir del estético; de ahí que, para el filósofo-poeta, cultivar el carácter estético, hacer que el hombre sensible transforme antes su naturaleza, que someta su existencia física a la forma y que se vuelve tan estético como sea posible, llega a ser uno de los cometidos más importantes de la cultura. Sólo esto ayudará a crear los fundamentos espirituales para el ennoblecimiento del hombre, sobre los cuales se dará el estado libre del futuro, que garantice que por medio de la belleza caminemos hacia la libertad.

Pero, ¿cómo se da ese paso (el más difícil para Schiller) que va del estado físico al estado estético, que pasa de la pura y simple existencia ciega a la forma? ¿Cómo se da ese salto de un estado de dependencia a un estado de independencia y libertad, ese tránsito del estado pasivo del sentir al activo del pensar y del querer? La clave, para esclarecer el modo como este tercer carácter nos ayuda a pasar de la necesidad a la libertad, del sentir al pensar, está para Schiller en dar un paso atrás, realizar una especie de genealogía hacia:

un momento, tanto en la evolución del conjunto de la especie, como en la del individuo, en el que el hombre aún no ha alcanzado su perfección y sólo uno de los dos impulsos actúa en él. [...] El impulso sensible actúa [...] antes que el racional, porque la sensación precede ${ }^{30} \mathrm{Ibid} .$, p. 305. 
a la conciencia, y en esta prioridad del impulso sensible, encontramos la clave de toda la historia de la libertad humana". ${ }^{31}$

En virtud de ese "paso atrás", Schiller vuelve a un primer estado del espíritu que denomina infinitud vacía; a un estado que precede a la conciencia, que se da antes de haber recibido la primera impresión de los sentidos y que no ha de confundirse con vacío de infinitud, puesto que en este estado, -donde el impulso vital todavía no se ha opuesto al impulso formal, donde la infinitud del espacio y del tiempo se ofrecen al libre uso de la imaginación-se da una carencia de determinaciones junto con un amplio mundo de lo posible, ya que en dicho estado no hay nada asentado y nada excluido. Pero si el hombre debe regresar a ese estado negativo de pura y simple determinabilidad, donde momentáneamente se halla libre de toda determinación, es para producir un cambio que unifique la indeterminación y la determinabilidad ilimitada con el contenido más completo posible, para que de este estado resulte inmediatamente algo positivo. La tarea consiste en suprimir y conservar, lo cual es posible oponiéndole otra determinación: ha de mantenerse la determinación que el hombre recibió de la sensación, porque el hombre ha de seguir siendo real; pero esta determinación, en cuanto limitación, debe ser suprimida para hacer posible una determinabilidad ilimitada.

Si Schiller recomienda ir hacia atrás con el fin de sustituir la determinación pasiva del estado de naturaleza por una activa, es porque pretende que el paso de la sensación al pensamiento, del estado natural al estado ético mantenga dos instancias: la real y la activa. Esto se logra gracias a una disposición intermedia: a un Estado estético en donde se da un determinabilidad real y activa, en la que la sensibilidad (que adquiere otro estatus) y la razón actúan simultáneamente, anulando recíprocamente su poder de determinación. En esa disposición intermedia, que representa el paso más difícil, el ánimo no se ve coaccionado ni física ni moralmente; sin embargo, actúa de ambas maneras, por

${ }^{31}$ Ibid., p. 281. 
lo cual merece ser considerada como una disposición libre. De tal modo que:

mediante esta disposición estética del ánimo, la actividad propia de la razón comenzará ya en el terreno de la sensibilidad, el poder de la sensaciones será contenido ya dentro de sus propios límites, y el hombre físico será ennoblecido de tal modo, que de aquí en adelante al hombre espiritual le bastará con desarrollarse a partir del hombre físico, siguiendo las leyes de la libertad. ${ }^{32}$

Pero aún subsiste la pregunta: ¿cómo es posible que la libertad haya nacido de lo no libre? Para responder a esta cuestión, el pensamiento schilleriano ofrece un giro hacia la naturaleza. Para él, es la disposición estética del ánimo la que da origen a la libertad; ésta no surge de la libertad, ni tampoco tiene origen moral: "Tiene que ser un regalo de la naturaleza; sólo el favor de la fortuna puede romper las cadenas del estado físico y conducir al salvaje a la belleza". ${ }^{33}$

Schiller circunscribe el ámbito de la libertad estética, marca su diferencia con respecto a la libertad moral y con esto evita el peligro del esteticismo, pero, al mismo tiempo, le da a la libertad estética un poder nunca visto. Si nuestro autor menciona que la conciencia sensible realiza su primera experiencia de libertad con respecto al mundo de la reflexión, esto no significa que dicho estado de libertad estética se refiera a una libertad que interfiera en nuestros conocimientos y en nuestra manera de ser y pensar. Por una parte, el ánimo estético, esa infinitud plena, no se refiere directamente a nuestro estado sensible ni al entendimiento, tampoco a la voluntad (a su cualidad moral), ya que no es considerado como un objeto de elección para un ser racional. Pero,

${ }^{32}$ Ibid., p. 307. "Lo bello es, sin duda, una expresión de libertad, pero no de aquella que nos eleva sobre el poder de la naturaleza y nos desliga de toda influencia corpórea, sino de la que gozamos como hombres en el ámbito de la naturaleza." Schiller, Sobre lo sublime, 1992, Granada, Editorial Ágora, p.105.

${ }^{33}$ Schiller, Cartas sobre la educación estética, p. 343. Para Schiller, sólo el estado estético no remite a un estado anterior; "sólo el estado estético es un todo en sí mismo, porque aúna en sí todas las condiciones de su origen y de su duración. Sólo en él nos sentimos como fuera del tiempo y nuestra humanidad se muestra con tal pureza e integridad, como si no hubiera sufrido ningún daño por la intromisión de fuerzas externas." Ibid., p. 295. 
por otra parte, dicho ánimo resulta ser la condición necesaria para llegar al conocimiento y a una manera de ser y pensar. ${ }^{34}$ Para Schiller el ánimo estético presenta tal amplitud que "puede referirse a la totalidad de nuestras diferentes fuerzas, sin ser un objeto determinado para ninguna de ellas en particular, y ésta es su cualidad estética". ${ }^{35}$ Mientras que cualquier otra actividad le impone al ánimo un límite determinado, sólo el ánimo estético conduce a lo ilimitado. Al no excluir ciertas realidades e incluir absolutamente a todas, no aplica en él la limitación, sino la infinitud. Al ser un estado de máxima realidad por la ausencia de limitaciones, y por la suma de fuerzas que actúan conjuntamente en él, el ánimo estético llega a ser, para Schiller, el estado más productivo, tanto para el conocimiento como para la moralidad, ya que, al no defender exclusivamente ninguna función particular de la humanidad $\mathrm{y}$ al favorecer sin distinción a todas sin preferencias, es el principio que las hace posibles a todas sin determinar su uso. "Lo único que consigue la cultura estética es que el hombre por naturaleza, pueda hacer de sí mismo lo que quiera, devolviéndole así por completo la libertad de ser lo que ha de ser". ${ }^{36}$

Mientras que en el estado dinámico del derecho el hombre limita su actividad, ya que se enfrenta a los otros hombres como una fuerza contra otra fuerza; y en el estado ético del deber el hombre, esgrimiendo la majestad de la ley, encadena su voluntad al imperativo del deber, y hace posible la sociedad moralmente necesaria limitándonos, al someter la voluntad individual a la voluntad general, pues frente a la ley moral siempre nos encontramos en una condición de sumisión; sólo el estado estético nos deja libres de la idea de constricción de la naturaleza; éste le devuelve al hombre la libertad que le fue arrebatada en el estado sensible por la coacción unilateral de la naturaleza, así como la libertad que le fue arrebatada por el pensamiento, por la

${ }^{34} \mathrm{Si}$ la belleza puede conducir a los hombres de la materia a la forma, de los sentimientos a las leyes, de una existencia limitada a una absoluta, no es por servir de ayuda al pensamiento, lo cual es contradictorio, "sino sólo procurando libertad a las fuerzas del pensamiento, para que se manifieste según sus propias leyes.” Ibid., p. 271.

${ }^{35}$ Ibid., p. 285.

${ }^{36}$ Ibid., p. 291. 
legislación exclusiva de la razón, por esa ley moral abstracta. Le devuelve la libertad como el don supremo de la humanidad. Cuando la razón no se ha manifestado en el hombre, o aún no se ha purificado lo bastante de los sentidos que lo dominan, el hombre sólo siente las cadenas del deber que impone la razón (la ley moral que se manifiesta sólo como prohibiciones y en contra del interés sensible del hombre), y no la liberación infinita que ésta procura. Se encuentra lejos de entender la dignidad del legislador que hay dentro de él, ya que para esto requiere del estadio estético:

No sólo es una licencia poética, sino también una aserción filosófica correcta, denominar a la belleza nuestra segunda creadora. Pues aunque la belleza sólo hace posible la humanidad, y deja después a cargo de nuestra voluntad libre hasta qué punto queremos realizar esa humanidad, actúa entonces del mismo modo que nuestra creadora original, la naturaleza, que no nos otorgó otra cosa que la disposición hacia la humanidad, pero dejando la aplicación de la misma en manos de nuestra propia voluntad. ${ }^{37}$

En este momento, la pregunta a realizar es si a partir del papel que se le atribuye a la dimensión estética, a la libertad estética, el pensamiento de Schiller le da un nuevo estatus a la sensibilidad y a la materia. Esto, en un primer momento, parece afirmativo, ya que el pensador sostiene que el paso al estado moral que se produce en virtud de un estado de libertad estética no excluye a la materia. Para Schiller, la belleza, esa ciudadana de dos mundos, como la caracteriza en Sobre la gracia y la dignidad, nos enseña que el hombre ya es libre en el seno de la sensibilidad: que el hombre para manifestarse como espíritu no tiene porque escapar de la materia. ${ }^{38}$ También afirma que el ser humano ya cumple su determinación física con una cierta libertad de espíritu, según las leyes de la belleza, y esto no lo hace contradiciendo su finalidad física, ya que, desde la óptica schilleriana, los fines de la naturaleza no determinan el modo, la forma de actuación, sino que las exigencias

${ }^{37}$ Ibid., p. 293.

${ }^{38}$ Véase ibid., p. 341. 
que impone la naturaleza se refieren sólo a lo que hace, al contenido de sus acciones y no a la forma.

¿Pero, con esto, se ha dado una nueva manera de relacionarse con la sensibilidad? Primero, debemos mencionar que la dimensión estética schilleriana, ese estado de "pura posibilidad sin límites" presenta una ambigüedad; así lo percibe Terry Eagleton, ${ }^{39}$ para quien el ánimo estético schilleriano parece suprimir lo que posibilita al no orientarnos de antemano a ninguna actividad definida, y a la vez, al servir a cualquiera, el ánimo estético se arriesga a dejarnos inmovilizados. ${ }^{40} \mathrm{Al}$ no privilegiar a ninguna facultad, ya que es condición de posibilidad de todas, el ánimo estético toma la forma de una neutralización de los contenidos, terminando en el mismo formalismo de la ley moral al que el pensamiento de Schiller intenta trascender. Así, para Eagleton, el estado estético, al estar emancipado de todo tipo de determinación, nos lleva a un mundo hipotético, a un perpetuo "como si", en el que sentimos nuestros poderes y capacidades como posibilidades puramente formales.

${ }^{39}$ Véase Terry Eagleton, La estética como ideología, 2006, Madrid, Editorial Trotta, trad. Germán Cano y Jorge Cano, pp. 161-80. Eagleton considera lo estético schilleriano como una reconstrucción ideológica, como una estrategia hegemónica que lleva a cabo el objetivo de la razón. Algo que no puede realizar la teoría kantiana donde la ley moral nos humilla, y al hacerlo, se ve imposibilitada para convertirse en una ideología efectiva, incapaz de generar lazos entre los individuos, de lograr armonía en la sociedad, cosa que sí logra la belleza schilleriana, ya que es la única que hace a todo el mundo feliz. Para Eagleton, si quiere preservar su dominio, el poder político debe implantarse en la misma subjetividad, producir un ciudadano cuyo deber ético-político ya haya sido interiorizado como inclinación espontánea, que consigue lo estético en Schiller. Eagleton señala que en Sobre la gracia y la dignidad la virtud es entendida como inclinación al deber, donde la moralidad se vincula con la inclinación y se convierte en una especie de segunda naturaleza, lográndose una transfiguración del deber ético en hábito instintivo.

${ }^{40}$ Inmovilización que Schiller profundiza en ese laboratorio que es su teatro. Lo vemos en el personaje de Walenstein, quien pretende ser hombre de poder y de posibilidades, quiere conservar sus opciones, pero como hombre de poder, debe actuar. Teme la irreversibilidad de las acciones, ya que éstas cierran el regreso a la posibilidad; es conciente de que la acción por la que nos decidimos nos toma cautivos, nos enreda en su lógica, aunque seamos nosotros sus productores. El mismo Walenstein nos habla del secreto que detiene su acción: "cerróse a mis espaldas toda salida; mis propias obras alzaron en torno un muro que me aprisiona y me impide retroceder. [...] Encerradas en mi alma, era todavía señor de mis acciones; una vez escapadas del asilo donde se engendraron, lanzadas de allí a la corriente de la vida, son juguetes de las maléficas divinidades que nada puede ablandar." Schiller, La muerte de Wallenstein, 1984, México, Editorial Porrúa, trad. José Ixart, p. 87. 
Para dicho autor, Schiller no está proponiendo un acercamiento diferente para la sensibilidad. Para él, la libertad negativa, la libre determinabilidad a la que llega la reflexión schilleriana lo único que hace es suprimir las presiones mutuas entre la sensibilidad y la razón. Para él, con lo estético schilleriano estamos ante la matriz del pensamiento y de la acción, que no ejerce ningún dominio sobre lo que alumbra y simplemente allana el camino para la aparición de la razón, mientras que Eagleton nos dice que la razón en el terreno estético se mezcla hábilmente en el ámbito de la sensualidad, refinándolo desde dentro y conduciéndolo a la obediencia de sus propios mandatos. Percibe en el pensamiento de Schiller una razón "que, bajo el disfraz de lo estético, pasa clandestinamente al campo enemigo en el esfuerzo por conocer $y$, por tanto, llegar a dominar a su antagonista". ${ }^{41}$ Nosotros vemos la incapacidad de los márgenes en la oposición metafísica de la que parte Schiller. La división dualista entre razón y sensibilidad propia de la metafísica de la que parte su análisis, ya no se opone de una manera radical cuando aborda el tema de la libertad estética y su relación con la sensibilidad; en términos de Derrida ${ }^{42}$ pierden sus márgenes, sus líneas fronterizas. Aunque, reconocemos, Schiller no lleva está lógica hasta sus últimas consecuencias y su solución se acerca a la dialéctica hegeliana.

${ }^{41}$ Terry Eagleton, op.cit., p. 177. Eagleton ve en la estética schilleriana un carácter contradictorio: por un lado, nos da un modelo ideológico, y, por otro, mantiene una visión de las capacidades humanas y su posibilidad de elevarse. Su pensamiento estético reconfigura las relaciones entre ley y deseo, razón y cuerpo, que podrían ayudar a crear un orden social nuevo, pero para esto deben desarrollar una habilidad para funcionar como crítica social sin proporcionar simultáneamente condiciones para perpetuar lo dado.

${ }^{42}$ El pensamiento deconstructivista de Derrida trata de mostrar las ambivalencias filosóficas en un juego que invierte y deshace las oposiciones, desenmascarando la violencia oculta que la sustenta. Su pensamiento invierte, disloca, desestabiliza la jerarquía binaria del pensamiento occidental. Trastoca las oposiciones binarias de la metafísica, donde uno de los opuestos es privilegiado al estar del lado del lógos, y al estarlo, se convierte en fundamento, en principio, en origen que siempre es puro, intacto, idéntico a sí mismo; mientras que el otro, que se contrapone al lógos, es negativo, es derivado, es carencia, es diferencia. Su estrategia no se limita a detectar oposiciones, ni a absorberlas hegelianamente en un sistema superior (destruye la Aufhebung hegeliana), sino que desenmascara las oposiciones, cuestiona sus líneas fronterizas. Véase Derrida, Posiciones, 1997, Valencia, Editorial Pre-Textos, trad. M. Arranz. 


\section{EI carácter objetivo de la belleza: la libertad en la apariencia}

Por último si nos referimos a la belleza, que en un principio parecía del todo subordinada a la regeneración moral y política, vemos cómo ésta alcanza la autonomía a lo largo del pensamiento de schilleriano. En Las cartas a Corner ${ }^{43}$ Schiller se muestra contrario al carácter subjetivo de la belleza establecido por Kant, así como a la perspectiva exclusivamente receptiva de la estética. Su pensamiento pasa de la experiencia de lo bello a la constitución de lo bello, y nos da una definición sensible-objetiva de la belleza que, sin hacer a un lado su carácter sensible, se fundamenta de manera objetiva. Su punto de partida no es la experiencia en cuanto unidad de conocimiento objetivo (Kant), ni la unidad e identidad de la autoconciencia del yo (Fichte), sino la unidad del ser humano en cuanto carácter sensible-racional. Así, la deducción trascendental del concepto de belleza, que realiza como resultado de su lectura de la Crítica del juicio, no prescinde del testimonio de la experiencia, más bien se encuentra regida por el principio antropológico de la doble naturaleza del carácter humano. Para Schiller este concepto racional puro de la belleza deberá revelarse como una condición necesaria de la humanidad.

112 La superación del subjetivismo kantiano, que es tan importante para Schiller, se logra estableciendo objetivamente un concepto de belleza y legitimándolo completamente a priori, partiendo de la naturaleza de la razón práctica, del principio de autodeterminación de la voluntad. Así, nuestro pensador establece el carácter objetivo de la belleza a partir de la función reguladora de la razón práctica, en analogía con su principio de autonomía. Dicha analogía se refiere a acciones que no se producen mediante la razón práctica, que no se determinan desde la voluntad, pero que, sin embargo, concuerdan con su forma: la forma de la voluntad pura. Al tomar la forma y no la materia (el contenido) de la razón práctica, Schiller consigue que la belleza no se encuentre determinada desde el exterior, que se excluya todo principio externo de determinación, toda heteronomía. Con esto se alcanza una tipo de libertad

${ }^{43}$ Schiller, Kallias o sobre la belleza, 1999, Barcelona, Editorial Anthropos, trad. Jaime Feijóo y Jorge Seca. 
que, para diferenciarla de la libertad moral, Schiller reconoce sólo como un préstamo de la razón práctica, ya que para él, siguiendo a Kant, únicamente es libre lo suprasensible y no lo que cae en el terreno de los sentidos. Esta libertad reside en los sentidos, pero sólo como una analogía de los mismos respecto a lo suprasensible, y con esto se le presta al objeto estético la facultad de determinarse a sí mismo de una manera reguladora, mas no constitutiva, como en el caso del juicio moral, ya que, como menciona en Kallias, "esta analogía de un objeto con la forma de la razón práctica no es libertad de hecho, sino sólo libertad en la apariencia, autonomía en la apariencia". ${ }^{4}$

Y con esto entramos a la dimensión de la apariencia. El mismo impulso del juego, que anuncia el acceso a la humanidad del que ya hablamos, se encuentra indisolublemente inclinación al adorno y al juego: al goce en la apariencia. Así, para el filósofo-poeta, el hombre ve cumplida su humanidad en el juego, no en la realidad, sino en el mundo de la apariencia, que es obra de él. ${ }^{45} \mathrm{Y}$ aquí la exigencia de realidad y la inclinación hacia lo real se entiende más como una carencia; en cambio, el interés por la apariencia implica una ampliación de la humanidad, un paso decisivo hacia la cultura, ya que pone de manifiesto, por una parte, una libertad exterior que ha superado el dominio de la necesidad y el apremio de la existencia: una imaginación que puede desarrollar libremente sus capacidades, al no encontrarse estrechamente ligada a lo real, a la necesidad. Mientras que, por otra parte, manifiesta una libertad interior, ya que nos deja ver una fuerza que, independientemente de cualquier materia externa, se pone en movimiento por sí misma.

La libertad estética se diferencia de la necesidad lógica del pensamiento y de la necesidad moral de la voluntad (del deber), ya que las leyes con las que se comporta el ánimo estético no aparecen como coacción: la libertad estética se refiere a la pura apariencia. Así, decimos que un objeto es bello cuando se da autonomía en la apariencia, cuando

${ }^{44}$ Ibid., p. 19.

${ }^{45}$ Sustituye la relación de arte y naturaleza, por la oposición entre apariencia y realidad. Mientras que la realidad de las cosas es obra de las mismas cosas, la apariencia de las cosas es obra del hombre, y el ánimo que se deleita en las apariencias halla más placer en lo que hace que en lo que recibe. 
la forma parece que surge espontáneamente y sin intención. Y aunque Schiller reconoce que todo objeto bello ha de poseer y mostrar una forma, someterse a reglas y fines, para él, éstas deben ser disimuladas en extremo y aparentar que surgen de la naturaleza del objeto de manera completamente libre y espontánea. ${ }^{46}$ Así, desde la perspectiva schilleriana, una forma es bella si se explica a sí misma sin ayuda de un concepto, si no necesita que el entendimiento, facultad encargada de indagar las causas y ocuparse de las formas, reconozca reglas y fines, ya que si lo hace destruye toda apariencia de libertad. Se trata únicamente de que el objeto bello aparezca como libre y no que lo sea realmente, y si un objeto del mundo sensible se muestra determinado sólo por sí mismo, si aparece como libre al presentarse ante los sentidos de manera que no se aprecie ninguna influencia de la materia ni de una finalidad, lo consideraremos como un analogon de la determinación pura de la voluntad.

Pero un carácter, una acción, no son bellos cuando muestran, coaccionada por la ley, la sensibilidad del hombre al que corresponden, o bien cuando coaccionan la sensibilidad del espectador. En este caso infundirán meramente respeto, pero no afecto, inclinación; el mero respeto humilla a quien lo siente. ${ }^{47}$

Schiller -sensible a la descalificación rousseauniana de la excesiva atención a las formas en detrimento de la realidad-señala una distinción entre realidad y apariencia que evita el esteticismo. Ante la posibilidad de que la apariencia predomine sobre la realidad y que la belleza dicte leyes a la realidad; ante el peligro que implica el abandono del pensamiento analógico, que tiende a borrar las fronteras entre la apariencia estética y la realidad, que atañe tanto a la ética como a la acción política, nuestro pensador afirma que las apariencias tienen cabida en el mundo moral sólo en la medida en que sea apariencia estética, en la medida

${ }^{46}$ Para que se dé la belleza, el objeto tiene que aparecer libre de reglas y fines (especialmente de la utilidad que, al recordarnos la determinación y el uso del objeto, destruye la autonomía en la apariencia), ya que cualquier influencia evidente de una regla y una finalidad, que son conceptos y no intuiciones, se manifiesta como coacción y conlleva una cierta heteronomía.

$$
{ }^{47} \text { Ibid., p. } 87 .
$$


en que no sustituyen ni oculten la realidad. De ahí que diferencie la apariencia lógica, la apariencia que concierne a la realidad, de la verdad de la apariencia estética. ${ }^{48}$ Mientras que la apariencia estética es sincera, no pretende engañar al conocimiento pasando por ser real y se le aprecia por ser apariencia, por ser juego, la mera apariencia es simple engaño. La apariencia estética es autónoma, absolutamente independiente de la realidad y, en el momento en que toma en cuenta la realidad, el juicio estético desaparece, ya que a éste sólo le complace lo vivo en tanto apariencia y lo real sólo en cuanto idea. Pero esto quiere decir que la belleza y la moral no pueden coincidir, ya que "la belleza moral es el grado máximo de perfección del carácter humano, pues sólo se presenta cuando el deber pasa a formar parte de su naturaleza". ${ }^{49}$

Por último, ¿cómo puede buscarse en la experiencia un fundamento objetivo de la representación de la libertad, si siguiendo el razonamiento schilleriano los objetos en cuanto fenómenos no poseen ni muestran libertad y la libertad es una idea de la razón a la que no se adecua intuición alguna? Schiller responde que "ese fundamento objetivo tendría que ser aquella cualidad de las cosas, cuya representación nos obligue decididamente a engendrar en nosotros la idea de libertad, y a referirla al objeto". ${ }^{50} \mathrm{Y}$ en esta respuesta, aparte de utilizar la vía trascendental como fundamento de nuestra representación de lo bello, Schiller, en Kallias, recurre a un fundamento metafísico, a una segunda definición de la belleza como "naturaleza en conformidad con el arte". En dicha definición, el fundamento objetivo de la belleza se refiere a la cualidad de las cosas, a la representación de un objeto que, por medio de su carácter objetivo, nos obliga (ya que el juicio de lo

${ }^{48}$ Schiller diferencia el concepto de apariencia (Erscheinung) con el de apariencia estética (ästhetischer Schein). La simple apariencia alude al carácter fenoménico de los objetos en el mundo sensible. La apariencia estética se refiere a la esencia de la belleza artística, de la obra de arte en cuanto forma de una forma. La apariencia estética es una apariencia sensible, pero formada, es lugar de autoconocimiento del hombre como naturaleza sensible-racional.

${ }^{49} \mathrm{Ibid}$., p. 39. Una acción libre resulta bella "cuando coinciden la autonomía del ánimo y la autonomía en la apariencia." Ibid., p. 39.

${ }^{50}$ Ibid., p. 43. 
bello debe contener necesidad y exigir el asentimiento general) a observar en él la cualidad de no estar determinado exteriormente. Definición que toma en cuenta a la naturaleza misma del objeto "cuando su perfección aparece como naturaleza" ${ }^{51}$ En esta segunda definición de belleza, Schiller dice preferir el término naturaleza que el de libertad, y con esto, una vez más, se congratula con lo sensible:

Prefiero el término de naturaleza al de libertad, porque designa además el campo de lo sensible, dentro del cual se delimita la belleza, y, junto al concepto de libertad, alude también a su esfera en el mundo de los sentidos. [...] Naturaleza en conformidad con el arte será, pues, aquello que se da una regla a sí mismo -aquello que se existe por medio de sus propias reglas. $^{52}$

${ }^{51}$ Ibid., p. 71.

${ }^{52}$ Ibid., pp.49-51. Con esto, la belleza en cuanto forma, alcanza una heautonomía: una autonomía impuesta a sí misma por sí misma. 